Review Article

\title{
Virucidal Effect of Medicinal Smoke for Mass Fumigation using Hawan Techniques during SARS-CoV-2 Pandemic: A Review
}

\author{
Neeta Kumar', Nalini Tripathi ${ }^{2}$, Divya Kanchibotla ${ }^{3}$, Munmun Kumari $^{4}, \underline{\text { Shyam Nandi }}^{5}$ \\ ${ }^{1,5}$ Scientist, Indian Council of Medical Research, India. \\ ${ }^{2}$ Research Scientist, VMMMC Medical College, New Delhi, India. \\ ${ }^{3}$ Director SSIAR, Bangalore, Karnataka, India. \\ ${ }^{4}$ Research Scientist, SSIAR Bangalore, Karnataka, India. \\ DOI: https://doi.org/10.24321/2394.6539.202009
}

I $\quad \mathbf{N} \quad \mathbf{F} \quad \mathbf{O}$

\author{
Corresponding Author: \\ Neeta Kumar, Scientist, Indian Council of Medical \\ Research, India. \\ E-mail Id: \\ neetakumar50@Gmail.com \\ Orcid Id: \\ https://orcid.org/0000-0002-7518-5068 \\ How to cite this article: \\ Kumar N, Tripathi N, Kanchibotla D, Kumari M, \\ Nandi S. Virucidal Effect of Medicinal Smoke for \\ Mass Fumigation using Hawan Techniques during \\ SARS-CoV-2 Pandemic: A Review. J Adv Res Med \\ Sci Tech 2020; 7(2): 22-28.
}

Date of Submission: 2020-06-15 Date of Acceptance: 2020-06-29

\section{$\begin{array}{llllllll}\mathbf{A} & \mathbf{B} & \mathbf{S} & \mathbf{T} & \mathbf{R} & \mathbf{A} & \mathbf{C} & \mathbf{T}\end{array}$}

\begin{abstract}
Even though many studies tested and found Hawan altering biome by killing pathogenic bacteria, fungus, and viruses. Studies are required to further validate its effect on load of viruses, its infectivity and if it can reduce occurrence of flu-like illnesses and their complications. In view of SARS-CoV-2 pandemic and its potential of community spread, one of the measure to curtail community spread may be Indian traditional mass fumigation technique of Hawan, which is considered as cultural practice for health and well being by offering ingredients of medicinal values in to fire. Such processing of specific ingredients through fire is considered turning them to nano-particles and act to alter biome. This paper reviews existing research evidences and suggests future mode of studies on viruses. This also highlights dearth of research capacity for estimation of virus content from the open air samples and the need to strengthen it through potential/ proposed technologies
\end{abstract}

Keywords: Virucidal Fumigation, Homa, Hawan, Airborne Virus, Medicinal Smoke

\section{Background}

Many of the viruses like SARS-CoV-2 transmission events are suspected to occur via aerosolized virus, travelling via selfcontained liquid droplets of $<5 \mu \mathrm{m}$ diameter. ${ }^{1}$ These small droplets can remain airborne for long periods, ranging from minutes to hours, resulting in far-reaching spread of airborne infection. ${ }^{2}$ Recent Chinese studies have reported SARS-CoV-2 also becoming air borne in nature. ${ }^{3,4} \mathrm{It}$ is evident also from Indian condition of $>1$ lakh new cases of Covid-19 despite using protective masks with high frequency of drug resistance, complications of multiple drug regimens, and side-effects. ${ }^{5,6}$ Testing and implementing air purification techniques of
Hawan for its virucidal efficacy with different ingredients will give insight for its translation potential during pandemic. Earlier, it was simply considered as religious practice; this review may come out as a comprehensive scientific knowledge about the effect of ethnopharmacological aspects $^{7}$ of the smoke of natural products for environment protection therapy and healthcare. Common preventive strategies like mask, PPEs may not be foolproof protection against SARS-CoV-2 transmission. ${ }^{8}$ Hence, sanitization of air stands strong as the solution worth exploring for prevention.

Standard Operating Procedure (SOP) described in Hawan/ 
Homa techniques of Vedic literature are done with different methods using different sets of ingredients of medicinal value with different effect on health and environment. Effect quantification has been widely published; however, such study especially for virucidal effect of infective respiratory corona family viruses are not many. Hence, this review is to take account of what is already evidence based and what more needs documentation by using modern methods of studies.

\section{Introduction to Vedic Fire Ceremonies/Homa/ Yagnya/Hawan}

Hawan/Yagnya as mentioned in Upanishads (500-700 BCE) as ritual of sacrifice around fire by the learned/ trained (skilled person-priest who has proper training to perform as per SOPs). It is an act by which something is surrendered to fire for the sake of the overall good effects. Such an act must rest on a sacred authority (āgama), and serve for man's salvation (śreyortha)-ApastambaYajnaParibhasasutras 1.1, Translator: M Dhavamony (Dhavamony 1974; Gonda 1980). Chandogya upnishad chapter 8 (700 BCE) has used word Hume for such techniques performed with utmost awareness, dedication meticulously by processing ingredients of medicinal values, in specific shaped vessels (Hawan Kund) ${ }^{9}$ along with different sound energies (Mantras) to get specified purifications of environment and well being of body. ${ }^{10}$

\section{Some Common Hawan Methods and Ingredients used}

According to target of effects, Hawan is named differently. Various ingredient used in hawan are called cake (puroḍ̄śa), pulse (karu), mixed milk (sāṃnāyya), an animal (paśu), the juice of soma-plant (soma) etc. It also consists of the smallest offerings of butter, flour and milk to serve the purpose of a sacrifice. With every type of hawan performing (vidhis), highly advanced beneficiary methodologies are associated. Sacredness and purity maintained during process is important. Particular shape of vessel (hawan kund) is different for different desired effects. Ingredients are mixture of medicinal herbs, roots, dry fruits, wood and ghee, etc. Medicinal valued ingredients are mostly comprised of any of these-Baheda, Bawachi, Bay Leaves, Cardamom Green, Chharil, Cloves, Daru, Haldi, Guggal, Jata Masi, Kapoor Kachari, Nutmeg, sandal Wood etc. Hawan may be named differently for different desired objectives to purify environment and improve health. Major techniques for good environment are: Lakshmi Ganapathi havan, Rudra havan, Navagraha havan, Nakshatra havan, Maha Mrityunjaya havan, Sudarshan havan, Lakshmi Narayana Havan, Chandi havan etc. Some common Hawan and ingredients used are:

Sudarshana Homa: The most ancient and sacred ceremony in the Vedic tradition which involves fire (the heat energy) with specialofferings like herbs, seeds, grains are cast into the fire along with chanting Sanskrit mantras (the sound energy). The active ingredients used in Sudarshana Homa are: Ghee, Sandal Wood, Puffed Rice, Honey, Turmeric Powder. Vaastu Shanthi Homas are attributed to cosmological considerations like the Sun's path, the rotation of the Earth, magnetic field, etc. Vastu Shanti Homa is described to remove negative energies and bestow harmony in a living/working space.The active ingredients used in Vastu Shanti Homa are: Palash, Pipal and Shami Wood, Ghee, Puffed Rice, Black Sesame seeds.

Pratyangira Homa: Ferocious form of the metabolic activity in environment, it has significant role in purifying the surroundings. The Homa is followed by the chorus sounds; ceremony is done using dried red chillies. The active ingredients used in Pratyangira Homam are: ghee, black pepper, puffed rice, nava dhanyam, shami and pipal wood etc.

Trayambakam Homa: It has significant role and impacts health of human beings and surroundings with use of durva grass and amrutha grass offered into the fire which is generated using specified hygienic purification techniques. Some active ingredients used in Triyambakam Homa are: Palash, Shami and Darbha Wood, Ghee, Rice and Sesame, Cow dung cake, etc.

Agnihotra: It is dedicated for environment purification and agriculture produce improvement. It is performed during sunrise and sunset using ingredients like locally available dry wood or cow dung cake with ghee and rice. ${ }^{11}$

Hawan/ Yajnya the ritual performed for the purification of the atmosphere through the agency of fire according to the Vedas (Vedic literature) and being established as scientific, least risky methods for air purification process. Different modes, mediums to produce fire, its different effect and uses in preparation/ processing of medicine has been defined in Rigveda. ${ }^{12}$ In early Indian writing (Sushruta 800-600 BC), the fumigation of an operating room with fumes of mustard, butter and salt was considered an early form of antisepsis of the air. During Plague epidemic by bacteria Yersinia pestis, fumigation was used by masses for prevention. Burning of incense and herbs were found reducing risk during plague. Though, there are studies establishing role of antiviral effect of medicinal smokes. Hydro-alcoholic extracts of various herbs used in hawan are established having antiviral, anti inflammatory activities. Medicinal smoke has been widespread practice in more than 50 countries, yet during Influenza epidemic, such practice needs urgent re-validation for effectiveness. ${ }^{13-16}$

The nano-sized-medicinal molecules produced by processing under fire as smokes of hawan, are capable permeating body through nose, lungs, and skin and manifest therapeutic effects of herbs, ${ }^{14}$ If performed as per standard operating 
procedures, It is considered effective and least risky mode of consuming medicines. ${ }^{3}$

\section{Published Research}

\section{Indian studies on Virucidal effects of Hawan: Health and environment}

In India, evidence of practice of Hawan by physicians/ Rishi/Muni is widely documented i.e. record of performing Agnihotra to purify environment is described in Rigveda under Swarasati-Indus valley civilization 7500 BC. Odoriferous and medicinal herbs offered in fire with chanting of Vedic mantra is described in details there..$^{15}$

The published scientific studies ${ }^{16,17}$ on various components of Hawan clearly demonstrate its beneficial effects on health and environment. ${ }^{18,19}$ For various brain disorders, nasal route and smock of medicine has been used in ancient times. It is now being tested using modern methods of research in studies like the one with epilepsy where patients of epilepsy were treated with hawan-smoke and smoke of volatile oils found to maintain level of medicine in body and prevented recurrence of fits successfully among epilepsy cases..$^{20,21}$ This study observed that sublimated vital elements and herbal medicines inhaled in Yagya first reach the brain, followed by lungs and other subtle components of the body. Thus, it has a direct healing effect on brain-born diseases and complexities. Crocus sativus L. Used in Hawan samgri contains constituents like crocetin, picrocrocin, safranal, though main component for characteristic aroma, Safranal/ Saffron modulated GABA neurotransmission and increased seizure thresholds.

Jatamansi, a reputed herb used in various multiple formulations of hawan is proven environment cleaner with health benefits. From cities in Maharashtra (India)-Beed, Pune and Ratnagiri, air samples were collected by using handy air sampler pre- and post-Hawan. Very high reduction in microbial counts $40 \%$ to $90 \%$ reduction in $\mathrm{SO}_{x}$ and $10 \%$ to $20 \%$ rise of $\mathrm{NO}_{x}$ resulted in the air of Hawan venues. Scientists observed clear up to 94 percent of airborne bacteria in the air. ${ }^{22}$

Research of Hawan process in treating various respiratory system illnesses also includes tuberculosis. ${ }^{23,24}$ Removal of agents of nosocomial infections in hospital settings has been tested in Gujrat. Air sampling was done by set plate method pre and post medicinal smoke arising after burning a mixture of wood of mango or pipal tree and medicinal herbs obtained from Shantikunj, Haridwar. Ritual was performed as per SOP in an indoor environment. Index of Microbial air contamination corresponds to the number of Colony-Forming Unit (CFU) counted on a petridish. Hawan process was performed after taking sample of biome on nutrient blood agar plates. 500 gm Samgri (mango and papal wood, camphor, jiggery, sandal wood, cypriol, giloy, barley, cow ghee etc.) medicinal herbs was burned and samples were collected to do microscopic characterization of colonies by Gram stain for colour, texture and size. Results showed over $95 \%$ reduction of aerial bacterial counts by $60 \mathrm{~min}$. Similar report showed micobicidal properties of hawan and purification of air. ${ }^{25}$

In view of frequent pandemics of FLIs and, now, Covid 19 (SARS-CoV-2) is turning to become air borne illness after initial spread by droplet Pushpender K et al recommended it essential sanitisation not only at personal level but also environment level for wide spread control of virus in air. 26,27

\section{International Studies}

Major evaluation of Hawan, outside India has been attempted by Mohagheghzadeh et al. They have done extensive review of medicine, source, its smoke and applications. They have listed four major medicinal plant families comprising ingredient for samgri those are Asteraceae, Solanaceae, Fabaceae, and Apiaceae as more than one-third hawan ingredient belong to these four. Majorly, leaves (up to $30 \%$ ) and fruit (15\%), root (12\%) and whole plant (12\%) are found to be used as samagri from these four families. Smoke effect has been listed as air purifier, skin ailment treatment, disinfectant for various gastrointestinal conditions, genital-urinary tract infections, mental and neurological conditions, joint pain, lung function improvement, pain in tooth, ear, eyes, etc. ${ }^{28}$

Recently, Korea tested turmeric smoke, characterized its carbon nanomaterial using a Nanodrop ND-1000 v 3.3.1 spectrophotometer, (Nanodrop Technologies, Inc., Wilmington, USA). The absorbance was scanned from 220-700 nm. The NC@TS was characterized using a JEM1400PLUS, Transmission Electron Microscope (TEM), USA. Further characterization was done using FTIR (Shimadzu FTIR-8300 spectrometer, San Diego, CA, USA) using KBr pellets. For FTIR, $\mathrm{KBr}$ was added directly into the beaker containing the smudge collected from the turmeric fumes. ${ }^{29}$ The antibacterial activity was determined via turbidometric assay using the spectrophotometer and also total viable count method using plate count technique. The Turmeric Smoke Smudges (TS) characterization revealed oval-shaped nanoparticles of turmeric. The sizes of these nanoforms varied from $5 \mathrm{~nm}$ to $500 \mathrm{~nm}$. Five bacterial strains: Streptococcus mutans, Salmonella enteritidis, Staphylococcus aureus, Pseudomonas aeruginosa and Escherichia coli tested and found controlled by turmeric smoke. Use of Caki 2 cell line (Caki-2 ATCC ${ }^{\circ}$ HTB-47 ${ }^{\text {TM }}$ ) purchased from American Type Tissue Culture collection, USA also showed anti-cancer activity of this smoke in this study and by others done with similar objectives. Studies from China and Iran also have established Hawan/medicinal smokes as effective methods of sanitisation. ${ }^{30}$ 


\section{Mechanism of Action Studies on Hawan}

Majority of studies have evaluated the bioactivity of the Hawan smoke as antioxidant and antimicrobial but mainly on bacteria and fungus, not in viruses31. Mahdavi et al tested the process of yagya to see if it magnifies the advantages of the desirable medicinal phyto-chemicals and other healthy nutritional substances. Mahdavi experimented with the fresh and dried leaves of Etlingera brevilabrum. Their pyrolysis/ burning were done in a fluidized-bed reactor under atmospheric nitrogen and air at different temperatures. They collected smokes, condensed to make it liquid and found microbicidal rich phenolic compounds (Phenol, 2-methoxyphenol, 2,6-dimethoxyphenol, and p-cresol) and Carboxylic acids (Mono-(2-ethylhexyl) phthalate and palmitic acids). This liquid also exhibited antioxidant activity of free radical scavenging and beta carotene bleaching. This liquid prevented growth 14 gram negative and positive bacteria and fungus. Antifungal properties were better than nystatin.

Rashmi et al. ${ }^{32}$ conducted laboratory tests by exposing fungus like Aspergillus, Penicillium, Alternaria, Curvularia, Cladosporium on petri-plates in a closed room with fumigation of plates by burning Hawan samagri (dried leaves of Mangifera indica, Azadira chtaindica and Santanum album) and recorded substantial fungus reduction. A compound, 1,2,3,4,6-penta-O-galloyl- $\beta$-D-glucopyranose (PGG), isolated from methanolic leaf extracts of Mangifera indica in mice found effective for anticonvulsant activity also has anti fungal property.

\section{Gap in Literature and Proposed Ideas for Future Research}

- From the metadata analysis, it is observed that Hawan has been designed by the ancient scholars to fight with a plethora of diseases. However, its quantitative estimation of virucidal role may further be researched and surely need validation of quantity with different amount and type of samagri used on designated air volume/ area sanitization per gram of samagri used. ${ }^{33,34}$ Improving air quality free from respiratory viruses requires studies focused on pre and post Hawan effect on virus and its infectivity/load in homa venue and area around.

- Incidences of respiratory infections in the persons attending different homas should be evaluated in follow-up for at least 6 months. Study participants may be persons with previous history of compromising respiratory morbidities like chronic bronchitis, asthma, dyspnoea, frequent FLIs. Either gender in all the age groups from vicinity/ venue of intervention should also be tested for FEV1, FEV5 vital capacity of lungs pre- and post-Hawan intervention.

- Virulence of virus requires certain amount of load of virus in contact of any individual to infest morbidity inside host. Generally, despite having constant presence of virus in atmosphere in air around, it is not infective due to basic immunity in body. Average load to surpass basic immunity is called dose for virulence of virus-Human Infectious Dose (HID). Though host immunity, type of pathogen, experimental setting affect the HID; however, studies required for SARSCoV-2 type infections like this one done estimating HID on volunteers. Volunteers were exposed to carefully titrated aerosolized influenza virus suspensions by inhaling through a face mask. The use of carefully titrated viral stocks enabled the determination of the minimal infectious dose by aerosol inoculation. The approximate $50 \%$ HID of virus per volunteer was from 1 to 126 TCID $_{50}$. TCID is plaque forming units which is sufficient to cause pathogenesis in $50 \%$ of the inoculated culture. Low or non-detectable antibody titres were of 0.6 to $3 \mathrm{TCID}_{50}$. Three $\log _{10}$ copies $/ \mathrm{mL}$ corresponded to $1 \mathrm{TCID}_{50} / \mathrm{mL}$. That is, one $\mathrm{TCID}_{50} / \mathrm{mL}$ contains 1000 copies of the viral genome. Aerosol infection dose for humans came about $1.95 \times 10^{3}$ viral genome copies/ genome load. ${ }^{35}$ Further research should aim at identifying the alteration in the HID of virus as a reflection of the impact of Homas in different and specific climate conditions.

- India requires studies of assessment of the impact of Homas on diversity and abundance of viral biomes and studies should be done using whole metagenomics approach by sampling of air from intervention location, Isolation and characterization of isolated virus particles, extraction of genomic DNA/RNA: (i) Without sedimentation of virus particles and (ii) from isolated virus particles. Bioinformatics analysis should be performed in view of viral identification, phylogenetic diversity of ss/ds-DNA and -RNA viruses. Analysis is required in view of spatial and temporal variation in viral biome. Relation of each microbiome distribution with meteorological parameters, genotypic differences in viral assemblages from the different land types/climate. Meteorological data for each sampling site may be downloaded from standard onsite weather station to analyse correlations of virulence and viral load.

- More studies are needed to analyze the impact of Homas on the mental well-being of the participants pre- and post-intervention. Appropriate questionnairebased assessment of the well-being of the participants, using scale of mental health in view of stress, anxiety, and emotional resilience associated with respiratory system related morbidity during pandemics. The outcome of such study should provide understanding of the impact of Hawan techniques on the purification 
of the environment as well as the wellbeing of the individuals performing/ attending Hawan.

- Air sampling devices and methods are not readily available in India for outdoor testing's; hence, capacity needs to be built on this technical deficit. Only some foreign studies have done virological profiling of air, nowhere in India it is done; hence, any study in this area will be pioneer for Indian conditions. It is necessary to mention here that the two different processes of air sampling and formation of aerosols for viral-NAs and other microbe's NAs are there. Techniques and tools needed to be refined for isolation of virus particles from the filtrates of the impregnate membranes/ aqueous solutions. In one set of experiments, genomic DNA may be directly extracted from the collected aerosol samples that should be subsequently used for the library generation of the bacterial/ viral population by following standard NGS protocols.

- Need of improved analysis software like Ion Reporter which includes, quality filtering of reads, clustering, taxonomy assignment, abundance and identification of microbial community including taxa identification (operational taxonomic unit classification), Heatmap, Comparative Analysis, Alpha Diversity (to know diversity within the sample), Beta Diversity (to know diversity between the samples), Krona plot (visualization tool that allows intuitive exploration of relative abundance and confidence within the complex hierarchies of meta-genomics classifications). After pre-processing of the raw data for the viral genomic DNA, similar bioinformatics analysis may be conducted to discover the alteration in the virome of the surrounding environment at a distance of (i) 0-meter; (ii) 50-meter; (iii) 200-meter; and (iv) 500-meter and so on to test catchment area affected by Hawan intervention.

- Though kits for virus / or its antibody detection in body fluids, for virus typing have been widely developed, environmental Air Sample Collection methods / tools are not given that attention. Infectious agents that can be transmitted via air include some of the most economically important pathogens as is evident during lockdown affecting economy. Collection of virus from aerosol is a challenging task and has been evaluated by many researchers outside India with variable sensitivity and efficacy. ${ }^{36}$ Recently, a cyclonic air collector (Midwest Microtek, Brookings, SD) was used in field study to assess airborne dissemination of swine viruses. ${ }^{37}$ The biological and technical repeat's sample' Nucleic Acid (NA) pooled to do the pyro-sequencing, in the process of air sampling and formation of aerosols for viral-RNAs and other microbe's RNAs in standard protocols in such studies and similar attempt are required in India. ${ }^{38}$

- Airborne transmission of the virus (also in case of
SARS-CoV-2) contributes significantly to the spread of this infectious particularly over large distances when carried by aerosol droplets with variable survival times. ${ }^{39}$ Efficient sampling of virus-loaded aerosol in combination with a low limit of detection of the collected virus could enable rapid and early detection of airborne virus at the point-of-care setting. A study have successful sampled and detected airborne influenza virus using system specifically developed for such applications-custom-made electrostatic precipitation (ESP)-based bioaerosol sampler, if coupled with downstream quantitative polymerase chain reaction (qPCR) analysis ${ }^{40}$ it can assess load and virulence of virus in air but needs replication in India.

- Virus can be tested in aerosolised air samples and liquidbased samplers. However, efficiency of these samplers needs validation and indigenous technology may reduce cost of equipment like costly liquid impingers, solid impactors, filters, electrostatic precipitators, etc. PCR techniques assess virus when it is no longer infective as processing of samples alters infectivity. Better filters which do not cause damage to viruses and more efficient in determining infective viral loads in aerosols also needs to be developed in house. In view of astonishing diversity of constitution of biome, care needs to be taken that a representative sample should contain nano-particles together with larger airborne particles. ${ }^{41}$ Virus antigens have to be collected in air with good efficiency and high sensitivity. ${ }^{42}$

- Purification of Virus Particles (VPs): Indigenous machines for virus and bacteria enumeration, viral morphology, Viral DNA/RNA extraction and sequencing using bioinformatics analysis, quantitative Reverse Transcription-Polymerase Chain Reaction (RT-PCR) (method widely used). ${ }^{43-48}$

- $\quad$ Focused studies are required to test Hawan techniques with and without sound energies used as Mantra during medicinal herbs processing in fire. There should be viral load and infectivity assessment pre- and post-Hawan techniques with and without Mantra.

\section{Conclusion}

Finally, there is lot of research already done to explore effectiveness of medicinal smoke/ hawan/ yagya for mass fumigation techniques of vedic tradition of India, still there are gaps and need urgent action in view of ongoing crisis.

Majority of RNA viruses during pandemic are corona viruses, mutated at a high rate (Steinhauer 1986). Within any one afflicted individual, corona virus' particles do not show a homogeneous population. Instead, they function as a pool of genetically variant strains known as quasispecies. This is due to the high error frequency of RNA polymerases, the presence of deletion mutants, the high 
frequency of RNA recombination and point mutations, and the occurrence of Defective-Interfering RNA (DI RNA). The medicines given orally are also under experimental stage. Hence, it is important to take protection techniques which are fast acting, safe, beneficial especially for those who are old, immune-compromised and cannot build further immunity to fight diseases. Making air cleaner from of viruses by reduction of HID is possible/ doable by mass fumigation techniques of Hawan. Cost wise also it may become highly cost-effective control measure in pandemic time but needs validation for cost and technical aspects enumerated in review.

\section{Conflicts of Interest: None}

\section{References}

1. Richard M, Ram F. Influenza a virus transmission via respiratory aerosols or droplets as it relates to pandemic potential. Femsmicrobiol rev 2016; 40: 68-85.

2. Yang W, Elankumaran S, Marr LC. Concentrations and size distributions of airborne influenza a viruses measured indoors at a health centre, a day-care centre and on aeroplanes. J R Soc Interface 2011; 8: 1176-1184.

3. Setti L, Passarini Fd, De Gennaro G, Barbieri P, Perrone M.G, Borelli M et al. Airborne Transmission Route of COVID-19: Why 2 Meters/6 Feet of Inter-Personal Distance Could Not Be Enough. Int J Environ Res Public Health 2020; 17: 2932.

4. Morawska L. Airborne transmission of SARS-CoV-2: The world should face the reality. Environment International 2020; 139: 105730.

5. Rajani R. Joshi M. Yagyopathy versus oral and iv drug administration: evaluation for pulmonary tuberculosis using compartment modeling. Journal of Ethnopharmacology 2008: 119(3): 501-506.

6. Mishra A, Batham L, Shrivastava V. Yagya therapy as supportive care in cancer patients improved quality of life: case studies. Interdisciplinary journal of yagya research 2018; 1(1): 26-33.

7. Braithwaite M, Vuuren SF, Viljoen AM. Validation of Smoke Inhalation Therapy to treat Microbial Infections. Journal of Ethnopharmacology 2008; 119(3): 501-506.

8. Milton DK, Fabian MP, Cowling BJ, Grantham ML. Influenza virus aerosols in human exhaled breath: particle size, culturability, and effect of surgical masks. Plospathog 2013; 9: e1003205.

9. Brahmavarchas (ed.). Yagyachikitsa (first ed.). Shrived mata gayatri trust, Shantikunj, Haridwar (Uttarakhand), 249411, India.

10. Viswanathagl M, Shylaja H, Yuvaraj HC, Sunil V. Anticonvulsant activity of 1,2,3,4,6-penta-o-galloyl- $\beta$ - $d$ glucopyranose isolated from leaves of mangiferaindica. Naunynschmiedebergs arch pharmacol 2013; 386: 599-604.
11. Golechha GR, Sethi IG, Deshpande, Usha Rani. Agnihotra in the treatment of alcoholism. Indian J Psychiatry 1991; 33(1): 20-26.

12. Pranayabhang. Purification of ambient air by performing somyagyajnya. International Journal of Environmental Sciences 2016; 6(5): 11.

13. Roy S, Chaurvedi S, Chowdhary A. Evaluation of antiviral activity of essential oil of Trachyspermum Ammi against Japanese encephalitis virus. Pharmacognosy Res 2015; 7(3): 263-267.

14. Brahmavarchas (ed.). Yagya se rog-nivaranevambasamvarddhankedolabh. In yagya- eksamagraupcharprakriya (pt. Shriramsharmaacharyavangmay no. 25) 1994; 1-12.6: 281003.

15. https://ia800102.us.archive.org/12/items/ rigvedacomplete/Rig\%20Veda\%20Complete\%20 \%28Sakala\%20Shakha\%29.pdf accessed on 25 May 2020.

16. Saxena M, Sengupta B, Pandya P. A study of the impact of yagya on indoor microbial environments. Indian Journal of Air Pollution Control 2007; 7(1): 6-15.

17. Saxena M, Sengupta B, Pandya P. Effect of yagya on the gaseous pollutants. Journal of air pollution control 2007; 7(2): 11-15.

18. Niharika S, Anita G. Management of atmosphere and health using hawan technique - a review. Current science 2019; 20(2).

19. Bansal P, Deepkaur R, Gupta V, Kumar S. Is there any scientific basis of Hawan to be used in epilepsyprevention/cure?, Current Traditional Medicine 2016; 2: 22-33.

20. Nnautiyan CS, Singh Chouhan P, Laxmannene P. Medicinal smoke reduces air borne bacteria, Journal of Ethnopharmacology 2007; 114: 446-451.

21. Mohagheghzadeh A, Faridi P, Shams-ardakani M,Ghosemi, Y. 2006.Medicinal smokes, Journal of Ethnopharmacology, 108 920, 161-184.

22. Morris CE, Sands DE, Bardin M, Jaenicke R, Vogel $B$, leyronas $C$. Microbiology and atmospheric processes: research challenges concerning the impact of airborne micro-organisms on the atmosphere and climate. Biogeosciences 2011; 8(1): 17-25.

23. Nautiyal CS, Chauhan PS. Medicinal Smoke Reduces Airborne Bacteria. Journal Of Ethnopharmacology 2007; 114(3): 446-51.

24. Raghuvanshi M, Pandya P, Joshi RR. Yagyopathic Herbal Treatment of Pulmonary Tuberculosis Symptoms: A Clinical Trial. Alternative and Complementary Therapies 2004; 101-105.

25. Samanth TU, Jha S, Sinha V. Effect of smoke from medicinal herbs on the nosocomial infections in ENT outpatient department. Indian Journal of Otology 2018; 24(1): 9-12. 
26. Enkhtaivan G. Anti-influenza (H1N1) potential of leaf and stem bark extracts of selected medicinal plants of south India. Saudi J Biolsci 2016; 22: 532-538.

27. Pushpendra K, Sharma S, Ayub CN, Tripathi S, Ajnavi S, Dubey S. Agnihotra - a non conventional solution to air pollution, (IJIRSE) International Journal Of Innovative Research In Science \& Engineering 2019: ISSN (Online): 2347-3207.

28. Mohagheghzadeh A, Faridi P, Shams-ardakani, Ghasemi Y. Medicinal smokes. J Ethnopharmacol 2006; 108: 161-184.

29. Chun S, Muthu M, Gansukh E etal. The ethanopharmacological aspect of carbon nanodots in turmeric smoke. Sci rep 2016; 6: 35586.

30. Zhao Y, Aarnin Kaja, Wang W, Fabri T etal. Airborne virus sampling: efficiencies of samplers and their detection limits for infectious bursal disease virus (ibdv). Ann agric environ med 2014; 21: 464-471.

31. Mahdaviw B, Yaacob WA. Phytochemical study of medicinal smokes from etlingerabrevilabrum leaves. Journal of Herbal Medicine 2018; 13: 52-62.

32. Tewary R, Mishra JK. Hawan-an effective method to reduce fungal load at small work places. Aerobiologia 1997; 13: 135-138.

33. Miraghaee SS, Karmi I, Becker LA. Psychobiological assessment of smoke of agarwood (aquilaria spp.) In male rats. JABS 2011; 5: 45-50.

34. Abhang P, Patil M, Moghe P. Beneficial effects of agnihotra on environment and agriculture. International journal of agricultural science and research 2015; 5: 111-20.

35. Saxena M, Kumar B, Matharu S. Impact of yagya on particulate matters. Interdisciplinary Journal of Yagya Research 2018; 1(1): 01-08.

36. Fabian P, Mcdevittjj, Houseman EA, Milton DK. Airborne influenza virus detection with four aerosol samplers using molecular and infectivity assays: considerations for a new infectious virus aerosol sampler. Indoor air 2009; 19: 433-441.

37. Corzo, CA. Airborne detection and quantification of swine influenza a virus in air samples collected inside, outside and downwind from swine barns. Plos one 2013; 8:e71444.

38. Ladhani I, Pardon G, Meeuws H, Van Wesenbeeck L, Schmidt K, Stuyver L et al. Sampling and detection of airborne influenza virus towards point-of-care applications. Plos one 2017; 12(3): e0174314.

39. Alonso C, Peter CR, Goyal S et al. Assessment of air sampling methods and size distribution of virus-laden aerosols in outbreaks in swine and poultry farms. J Vet Diagn Invest 2017; 29(3): 298-304.

40. Zuo, ZL. Association of airborne virus infectivity and survivability with its carrier particle size. Aerosol Sci
Technol 2013; 47: 373-382.

41. Verreault D, Moineau S, Duchaine C. Methods for sampling of airborne viruses. Microbiology And Molecular Biology Reviews2008; 72(3): 413-444.

42. Pan M, Lednicky JA. C.-Y. Wu. Collection, particle sizing and detection of airborne viruses. Journal of Applied Microbiology 2019; 127: 1596-1611.

43. Cao G, Blachere FM, Lindsley WG, Noti JD, Beezhold $\mathrm{DH}$. Development of a methodology to detect viable airborne virus using personal aerosol samplers. Epa/600/r-10/127, Environmental Protection Agency, Washington DC, USA, 2010. 